\title{
SISTEM PENDUKUNG KEPUTUSAN PEMILIHAN GURU TERBAIK PADA SMK MARIA GORETTI PEMATANGSIANTAR MENGGUNAKAN METODE SIMPLE ADDITIVE WEIGHTING (SAW)
}

( Studi Kasus : SMK Maria Goretti Pematangsiantar)

\author{
Rotua Sihombing Hutasoit ${ }^{1}$, Agus Perdana Windarto ${ }^{2}$, Dedy Hartama ${ }^{3}$, Solikhun $^{4}$ \\ ${ }^{1}$ Mahasiswa Program Studi S-1Sistem Informasi, STIKOM Tunas Bangsa Pematangsiantar, \\ ${ }^{234}$ Dosen STIKOM Tunas Bangsa Pematangsiantar, Sumatera Utara-Indonesia \\ Jalan Sudirman Blok A No. 1, 2, 3 Pematangsiantar \\ E-mail : rio.hutasoit@yahoo.co.id,zhantura.gusti@gmail.com,dedyhartama@amiktunasbangsa.ac.id, \\ solikhun@amiktunasbangsa.ac.id
}

\begin{abstract}
Abstrak
Memiliki guru, staf tenaga pengajar yang profesional merupakan sebuah keharusan bagi sekolah dalam melaksanakan proses pendidikan yang bermutu, demikian halnya dengan SMK Maria Goretti Pematangsiantar. Untuk itu, sekolah selalu mendorong peningkatan profesionalitas guru dengan cara memantau kerja guru dalam mengimplementasikan tugasnya sehingga dapat mencapai standar kompetensi yang telah ditentukan. Sistem pendukung keputusan secara umum didefenisikan sebagai sebuah sistem yang mampu menghasilkan pemecahan maupun penanganan masalah. Sistem pendukung keputusan tidak dimaksudkan untuk menggantikan peran pengambil keputusan, tapi untuk membantu dan mendukung pengambil keputusan. Dalam peranan sistem pendukung keputusan dalam konteks keseluruhan sistem informasi ditujukan untuk memperbaiki kinerja melalui aplikasi teknologi informasi serta menentukan pendekatan yang digunakan dalam proses pengambilan keputusan, sampai mengevaluasi pemilihan interaktif. Salah satu metode yang sering digunakan dalam sistem pendukung keputusan adalah metode Simple Additive Weighting (SAW). Metode Simple Additive Weighting (SAW) ini dipilih karena dapat menentukan nilai bobot untuk setiap atribut, kemudian dilanjutkan dengan proses perankingan yang akan menyeleksi alternatif terbaik dari sejumlah alternatif yang ada. Dalam hal ini alternatif yang dimaksud adalah penentuan guru terbaik pada SMK Maria Goretti Pematangsiantar menggunakan metode SAW (simple additive weighting). Dengan metode perangkingan tersebut diharapkan penilaian akan lebih tepat karena didasarkan pada nilai kriteria dan bobot yang sudah ditentukan sehingga akan mendapatkan hasil yang lebih maksimal.
\end{abstract}

Kata Kunci : Sistem pendukung keputusan; simple additive weighting; guru; SMK

\section{Pendahuluan}

Pada saat ini pemanfaatan ilmu pengetahuan dan teknologi berkembang dengan sangat cepat dan menghasilkan inovasi baru yang harus diimbangi dengan kemampuan beradaptasi terhadap teknologi tersebut. Salah satu bidang tersebut adalah sistem pendukung keputusan yang dapat membantu dalam pengambilan keputusan. Sistem Pendukung Keputusan sebagai sekumpulan tools komputer yang terintegrasi yang mengijinkan seorang decision maker untuk berinteraksi langsung dengan komputer, untuk menciptakan informasi 
yang berguna dalam membuat keputusan semi terstruktur dan keputusan tak terstruktur yang tidak terantisipasi.

Keputusan yang diambil diharapkan tidak subyektif agar kualitas yang diperoleh dapat sesuai dengan harapan sehingga tidak ada pihak yang dirugikan. Pengambilan keputusan untuk menetapkan apakah kinerja guru tersebut sudah memenuhi kualitas yang diterima atau tidak di dasari beberapa kriteria yang ditetapkan oleh sekolah.

Untuk menghindari subyektifitas keputusan yang dihasilkan diperlukan suatu sistem pendukung keputusan (SPK) yang dapat membantu menilai kinerja guru dalam memutuskan menjadi seorang guru yang terbaik. SPK merupakan suatu sistem menggunakan model yang dibangun untuk membantu menyelesaikan masalah-masalah semi terstruktur.

Metode Simple Additeve Weighting sering dikenal dengan istilah metode penjumlahan terbobot. Konsep dasar metode Simple Additeve Weighting adalah mencari penjumlahan terbobot dari rating kinerja pada setiap alternatif pada semua atribut. Metode ini membutuhkan proses normalisasi matriks keputusan ke suatu skala yang dapat diperbandingkan dengan semua rating alternatif yang ada.

Penelitian akan di lakukan di SMK Maria Goretti Pematangsiantar, karena penentuan guru terbaik di SMK Maria Goretti Pematangsiantar dilakukan pada saat hari guru nasional yang selalu diadakan pada tanggal 25 november setiap tahunnya, yang menentukan pemilihan guru terbaik di sekolah tersebut adalah kepala sekolah. Maka dalam menentukan pemilihan guru terbaik dibutuhkan sistem yang dapat membantu dalam menentukan penilaian, agar kesalahan dalam pemilihan guru terbaik tidak terjadi dan waktu dalam menentukan pemilihan guru terbaik lebih efektif.

Tujuan penelitian ini adalah membangun sebuah aplikasi sistem penunjang keputusan yang dapat digunakan oleh pihak sekolah Maria Goretti untuk menganalisa seberapa besar pengaruh kinerja guru terhadap optimalisasi pengembangan pendidikan khsususnya dalam PBM (Proses Belajar Mengajar) di SMK Maria Goretti, menentukan faktor yang paling mempengaruhi bagi proses optimalisasi sistem dan manajemen guru dan mengimplementasikan sistem pendukung keputusan dengan menggunakan metode Weighted Product dalam menganalisa bobot masing-masing faktor pendukung.

\section{Kajian Teori}

Sistem pendukung keputusan atau decision support sistem (DSS) merupakan sistem informasi interakif yang menyediakan informasi, pemodelan, dan pemanipulasian data (Kusrini, 2007). Sistem ini digunakan untuk membantu pengambilan keputusan dalam situasi yang semi terstruktur dan situasi yang tidak terstruktur, di mana tidak seorang pun tahu secara pasti bagaimana keputusan seharusnnya dibuat (Alter, 2002).

Sistem pendukung keputusan biasanya dibangun untuk mendukung solusi atas suatu masalah atau untuk mengevaluasi suatu peluang. Sistem pendukung keputusan yang seperti itu disebut aplikasi sistem pendukung keputusan. Apikasi sistem pendukung keputusan digunakan dalam pengambilan keputusan. Aplikasi sistem pendukung keputusan menggunakan Computer Based Information Sistem (CBIS) yang fleksibel, interaktif, dan dapat diadaptasi, yang dikembangkan untuk mendukung solusi atas masalah 
manajemen spesifik yang tidak terstruktur.

Aplikasi sistem pendukung keputusan menggunakan data, memberikan antarmuka pengguna yang mudah, dan dapat menggabungkan pemikiran pengambilan keputusan. Sistem pendukung keputusan lebih ditujukan untuk mendukung manajemen dalam melakukan pekerjaan yang bersifat analistis dalam situasi yang kurang terstruktur dan dengan kriteria yang kurang jelas.

Menurut pernyataan (Rivai \& Basri, 2004), kinerja merupakan hasil seseorang secara keseluruhan selama periode tertentu di dalam melaksanakan tugas, seperti standar hasil kerja, target atau sasaran, atau kriteria yang telah ditentukan terlebih dahulu dan telah disepakati bersama.

Penilaian Kinerja Menurut Simamora (1997), penilaian kinerja (performance appraisal) adalah proses dengannya organisasi mengevaluasi pelakasanaan kerja individu. Dalam penilaian kinerja dinilai kontribusi karyawan kepada organisasi selama periode waktu tertentu. Umpan balik kinerja (performance feedback) memungkinkan karyawan mengetahui seberapa baik mereka bekerja jika dibandingkan dengan standar-standar organisasi. Apabila penilaian kinerja dilakukan secara benar, para karyawan, penyelia-penyelia mereka, departemen sumber daya manusia, dan akhirnya organisasi bakal diuntungkan dengan pemastian bahwa upaya- upaya individu memberikan kontribusi kepada fokus strategik organisasi.

Suatu penilaian kinerja akan membutuhkan jawaban dari pihak penilai sesuai dengan hasil pengamatan dari kinerja yang ditampilkan oleh pihak yang dinilai. Jawaban merupakan dari pihak penilai dalam suatu penilaian karena dari jawaban ini akan dilakukan suatu pengelolahan sehingga menghasilkan suatu nilai akhir. Setiap jawaban dalam proses penilaian ini dijabarkan dalam bentuk suatu kriteria penilaian. Contoh kriteria penilaian dari variabel prestasi kerja dengan indikator pertamanya yaitu mempunyai keterampilan dalam melaksanakan tugasnya seperti tertera pada tabel dibawah ini.

\section{Metode Penelitian}

Pihak dari sekolah SMK Maria Goretti Pematangsiantar sering kali mengalami kesulitan dalam mendapatkan keputusan untuk menghitung dan menentukan sebuah keputusan untuk menilai guru-guru tersebut, perhitungan yang dilakukan terkadang mengalami kesalahan dan waktu yang cukup lama. Dengan terjadinya kesalahan dalam menentukan penilaian guru membuat sekolah SMK Maria Goretti Pematangsiantar mengalami banyak persoalan dengan penempatan guru dengan kinerja yang patut untuk di tiru oleh guru yang lain. Berdasarkan permasalahan maka di bentuk sebuah sistem pengkajian untuk memecahkan masalah yang di alami SMK Maria Goretti Pematangsiantar agar tidak mengalami kekeliruan dalam memberi penilaian terhadap guru tersebut dan menentukan guru terbaik.

Metode SAW sering juga dikenal istilah metode penjumlahan terbobot. Konsep dasar metode SAW adalah mencari penjumlahan terbobot dari rating kinerja pada setiap alternatif pada semua atribut.

\section{Metode Penelitian}

Metode SAW membutuhkan proses normalisasi matriks keputusan (X) ke suatu skala yang dapat diperbandingkan dengan semua rating alternatif yang ada. (Sri Kusumadewi, 2006 :74) Untuk mengetahui rumus dari 
metode Simple Additive Weighting dapat dilihat pada Gambar 3.1.

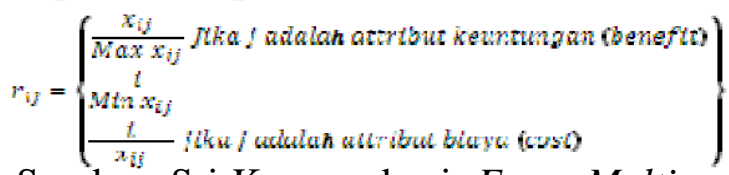

Sumber: Sri Kusumadewi, Fuzzy Multi-

Attribute decision Making, 2006

Keterangan :

rij = nilai rating kinerja ternormalisasi

xij = nilai atribut yang dimiliki dari setiap kriteria

Max $x i j=$ nilai terbesar dari setiap kriteria

Min $x i j=$ nilai terkecil dari setiap kriteria

Benefit = jika nilai terbesar adalah terbaik

Cost $=$ jika nilai terkecil adalah terbaik

Dimana: rij sebagai rating kinerja ternormalisasi dari alternatif $\mathrm{Ai}$ pada atribut $\mathrm{Cj}$; $\mathrm{i}=1,2, \ldots, \mathrm{m}$ dan

$\mathrm{j}=1,2, \ldots, \quad$ Nilai preferensi untuk setiap alternatif

$\mathrm{m}(\mathrm{Vi})$ dapat dilihat pada Gambar 3.2 berikut ini.

$$
V_{i}=\sum_{j=1}^{n} w_{j} r_{i j} \cdots
$$

\section{Hasil dan Pembahasan}

Pihak dari sekolah SMK Maria Goretti Pematangsiantar sering kali mengalami kesulitan dalam mendapatkan keputusan untuk menghitung dan menentukan sebuah keputusan untuk menilai guru-guru tersebut, perhitungan yang dilakukan terkadang mengalami kesalahan dan waktu yang cukup lama. Dengan terjadinya kesalahan dalam menentukan penilaian guru membuat sekolah SMK Maria Goretti Pematangsiantar mengalami banyak persoalan dengan penempatan guru dengan kinerja yang patut untuk di tiru olehguru yang lain. Berdasarkan permasalahan maka di bentuk sebuah sistem pengkajian untuk memecahkan masalah yang di alami oleh SMK Maria Goretti Pematangsiantar agar tidak mengalami kekeliruan dalam memberi penilaian terhadap guru tersebut dan menentukan guru terbaik.

Tabel 1. Data kinerja guru SMK Maria Goretti

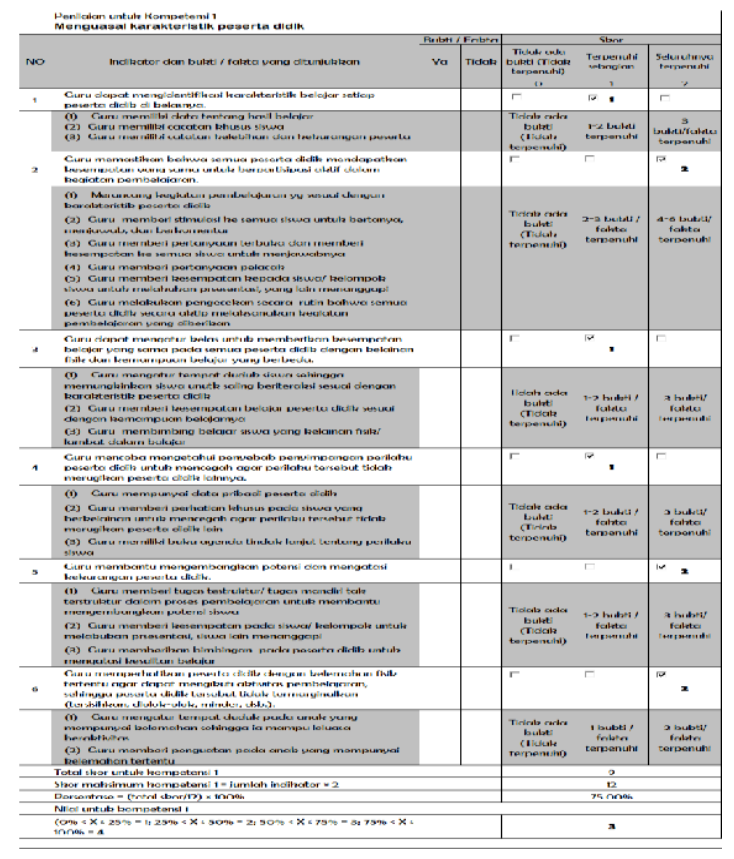

Terdapat 4 orang guru yang akan di nilai kinerjanya yang berdasarkan criteria-kriteria yang sudah di tentukan. 4 orang guru yang menjadi kandidat (Alternatif) tersebut adalah :

A1 = Juliansen Sinaga, S.Pd;

A2 = Arifin Sihombing, S. Pd;

A3 = Drs. Jalesman Saragih;

A4 $=$ Drs. Bernad Sianipar

Ada lima kriteria yang digunakan untuk melakukan penilaian yaitu :

$\mathrm{C} 1=$ Kedisiplinan : Sangat Baik

$\mathrm{C} 2=$ Prakarsa : Baik

C3= Prestasi : Baik

$\mathrm{C} 4=$ Tanggung Jawab : Cukup

C5= Menjaga Nama Baik : Cukup 
Pengambil keputusan memberikan bobot untuk setiap kriteria sebagai berikut :

$\mathrm{C} 1=30 \%$;

$\mathrm{C} 2=20 \%$;

$\mathrm{C} 3=20 \%$;

$\mathrm{C} 4=15 \%$;

$\mathrm{C} 5=15 \%$.

Ada beberapa langkah untuk melakukan perhitungan menentukan status penilaian guru menggunakan metode simple additive weighting (SAW) sesuai contoh diatas yaitu :

1. Langkah Pertama memberikan nilai dan bobot untuk setiap alternatif pada setiap kriteria yang sudah ditentukan.

Tabel 2. Nilai dan bobot

\begin{tabular}{cccc}
\hline \multirow{4}{*}{ Nilai } & C1, C2, C3, C4 Dan C5 \\
Tertulis & Bobot & $\begin{array}{c}\text { Nilai } \\
\text { Kriteria }\end{array}$ & Keterangan \\
\hline $80-100$ & 30 & 5 & Sangat \\
& & & Baik \\
$60-79$ & 25 & 4 & Baik \\
$40-59$ & 15 & 3 & Cukup \\
$20-39$ & 10 & 2 & Kurang \\
$0-19$ & 0 & 1 & Baik \\
& & & Tidak Baik \\
\hline
\end{tabular}

2. Langkah kedua, menentukan rating kecocokan.

Tabel. Rating Kecocokan dari setiap alternatif pada setiap kriteria

Tabel 3. Kriteria

\begin{tabular}{cccccc}
\hline \multirow{2}{*}{ Aternatif } & \multicolumn{5}{c}{ Kriteria } \\
\cline { 2 - 6 } & C1 & C2 & C3 & C4 & C5 \\
\hline Juliansen & 4 & 5 & 4 & 4 & 5 \\
Arifin & 5 & 5 & 4 & 4 & 4 \\
Jalesman & 5 & 4 & 4 & 4 & 5 \\
Bernad & 5 & 4 & 5 & 5 & 4 \\
\hline
\end{tabular}

3. Langkah ketiga pembentukan matriks keputusan dibentuk.

$$
\begin{aligned}
& x=\left[\begin{array}{lllll}
4 & 5 & 4 & 4 & 5 \\
5 & 5 & 4 & 4 & 4 \\
5 & 4 & 4 & 4 & 5 \\
5 & 4 & 5 & 5 & 4
\end{array}\right] \\
& x=\left[\begin{array}{lllll}
n_{11} & n_{12} & n_{15} & n_{24} & n_{15} \\
n_{11} & n_{22} & n_{25} & n_{24} & n_{25} \\
n_{11} & n_{12} & n_{13} & n_{14} & n_{15}
\end{array}\right]
\end{aligned}
$$

4. Langkah keempat hitungan nilai normalisasi dari setiap alternatif dengan rumus

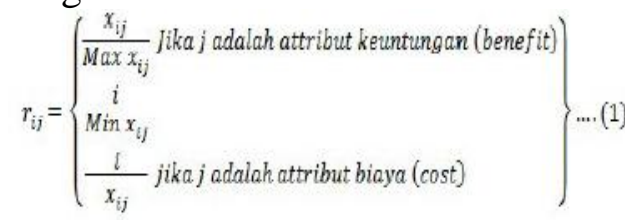

Gambar 1. Rumus normalisasi

Proses normalisasi :

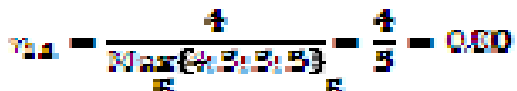

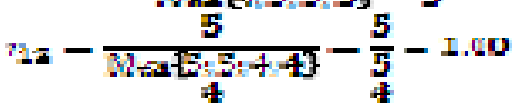

$$
\begin{aligned}
& n_{12}=\frac{4}{M a x-4+475)}=\frac{4}{5}=0.50 \\
& n_{-4}=\frac{4}{\ln \{t:-4+4\}}=\frac{4}{5}=0.50
\end{aligned}
$$

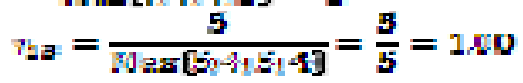

$$
\begin{aligned}
& \eta_{2}=\frac{5}{\operatorname{Nex}_{3}\left[\sin _{1}\right]}=\frac{5}{5}=1.00
\end{aligned}
$$

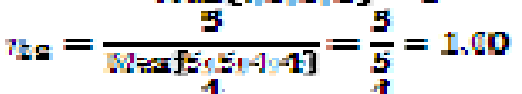

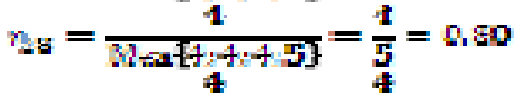

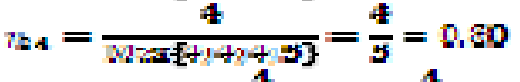

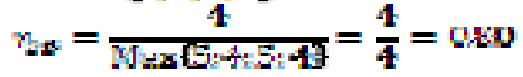

$$
\begin{aligned}
& r_{51}=\frac{5}{\operatorname{Nar}(4,3,3)}=\frac{3}{5}=180
\end{aligned}
$$

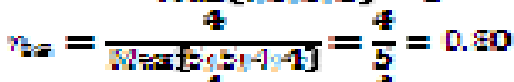

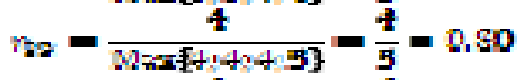

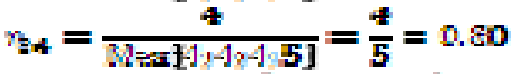

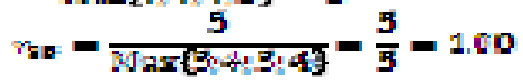

$$
\begin{aligned}
& v_{21}=\frac{3}{M_{4}\left[m_{0} E_{1} 5\right]}=\frac{5}{5}=1.60
\end{aligned}
$$

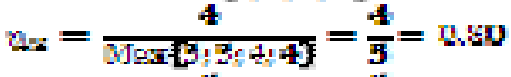

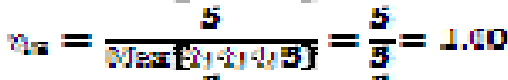

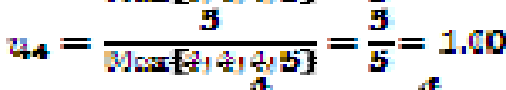

$$
\begin{aligned}
& v_{0}=\frac{1}{M ! x E: 4: 5:-4\}}=\frac{4}{4}=1.60
\end{aligned}
$$

Kemudian hasil normalisasi dibuat dalam matriks normalisasi :

$R=\left[\begin{array}{lllll}0.80 & 1.00 & 0.80 & 0.80 & 1.00 \\ 1.60 & 1.00 & 0.80 & 0.80 & 0.80 \\ 1.60 & 0.80 & 0.80 & 0.80 & 1.00 \\ 1.60 & 0.80 & 1.00 & 1.00 & 1.00\end{array}\right]$ 
5. Langkah kelima tentukan bobot yang akan digunakan untuk proses perankingan :

$\mathrm{w}=\left[\begin{array}{lllll}0,30 & 0,20 & 0,20 & 0,15 & 0,15\end{array}\right]$

6. Langkah-langkah keenam pencarian perankingan atau nilai terbaik dengan memasukan setiap kriteria yang diberikan dengan menggunakan rumus dengan perangkingan adalah sebagai berikut :

$\mathrm{V}_{1}=(0.30)(0.80)+(0.20)(1.0 \overline{0})+(0.20)(0.80)+$ $(0.15)(0.80)+(0.15)(1.00)=0.87$

$\mathrm{V}_{2}=(0.30)(1.00)+(0.20)(1.00)+(0.20)(0.80)+$ $(0.15)(0.80)+(0.15)(0.80)=0.90$

$\mathrm{V}_{3}=(0.30)(1.00)+(0.20)(0.80)+(0.20)(0.80)+$ $(0.15)(1.00)+(0.15)(1.00)=0.89$

$\mathrm{V}_{4}=(0.30)(1.00)+(0.20)(0.80)+(0.20)(1.00)+$ $(0.15)(1.00)+(0.15)(1.00)=0.96$

Hasil perangkingan dapat kita lihat sebagai berikut:

\begin{tabular}{lc}
\hline Aternatif & $\begin{array}{c}\text { Hasil } \\
\text { Perangkingan }\end{array}$ \\
\hline Juliansen & 0,87 \\
Arifin & 0,90 \\
Jalesman & 0,89 \\
Bernad & 0,96 \\
\hline
\end{tabular}

Di antara V1, V2, V3 dan V4 yang mendapatkan nilai terbesar adalah V4, sehingga kandidat (alternatif) yang terpilih yaitu V4 = Bernad.

Untuk menguji tingkat

keakuratan metode Simple Additive Weighting (SAW) dalam menentukan alternatif guru terbaik dari beberapa alternatif dalam menentukan faktor pendukung yang paling mempengaruhi dalam proses penilaian kinerja guru dibutuhkan suatu aplikasi sistem pendukung keputusan. Aplikasi ini dibangun dengan menggunakan bahasa pemrograman $v b$ dan aplikasi database menggunakan Acces. Untuk mengakses sistem ini menu yang pertama sekali muncul adalah menu login. Menu ini digunakan sebagai security hak akses bagi pihak yang mengakses sistem.

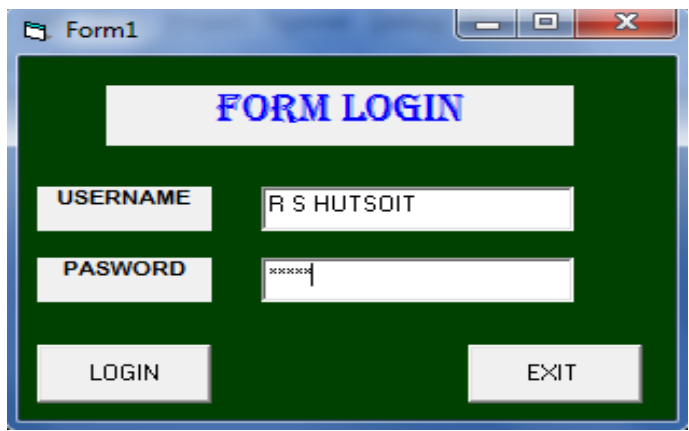

Gambar 1. Halaman login

Ketika user melakukan login maka menu selanjutnya yang akan tampil adalah halaman utama aplikasi sistem penunjang keputusan penilaian kinerja guru.

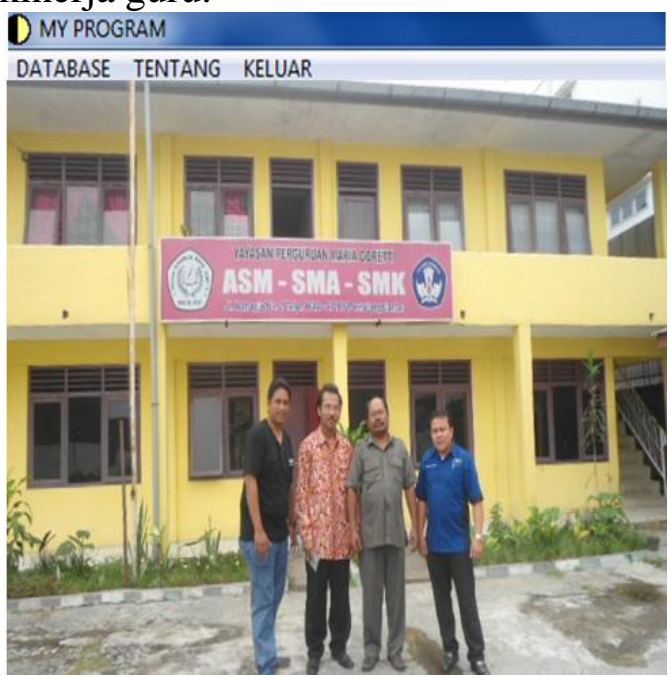

Gambar 2. Halaman menu utama

Untuk menganalisis faktor pendukung keputusan penilaian kinerja guru maka dibutuhkan informasi data guru. Dalam sistem ini data guru diolah dan disimpan pada database menggunakan halaman pengolahan data guru.

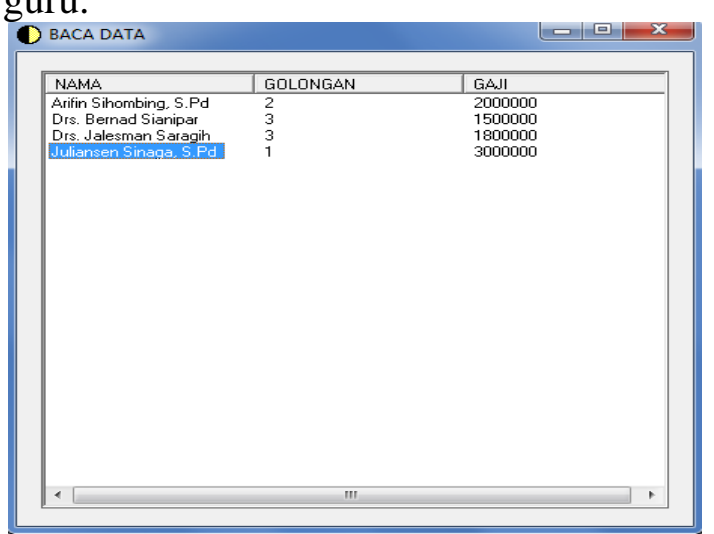

Gambar 3. Halaman data guru 
Untuk menganalisis faktor pendukung kinerja guru maka dijadikan alternatif pilihan criteria guru terbaik. Yang diukur berdasarkan kriteria sebagai berikut :

a. Kedisiplinan

b. Prakarsa

c. Prestasi

d. Tanggung Jawab

e. Menjaga Nama Baik Sebagai Pendidik

Masing-masing kriteria diukur dengan ketentuan sebagai berikut :

1 = Tidak Baik

$2=$ Kurang Baik

$3=$ Cukup

4 = Baik

$5=$ Sangat Baik

Berdasarkan ketentuan tersebut diatas pengambil keputusan memberikan bobot pada masing-masing kriteria. Untuk menganalisis faktor pendukung optimalisasi kinerja guru aplikasi sistem ini menggunakan metode Simple Additive Weighting (SAW)

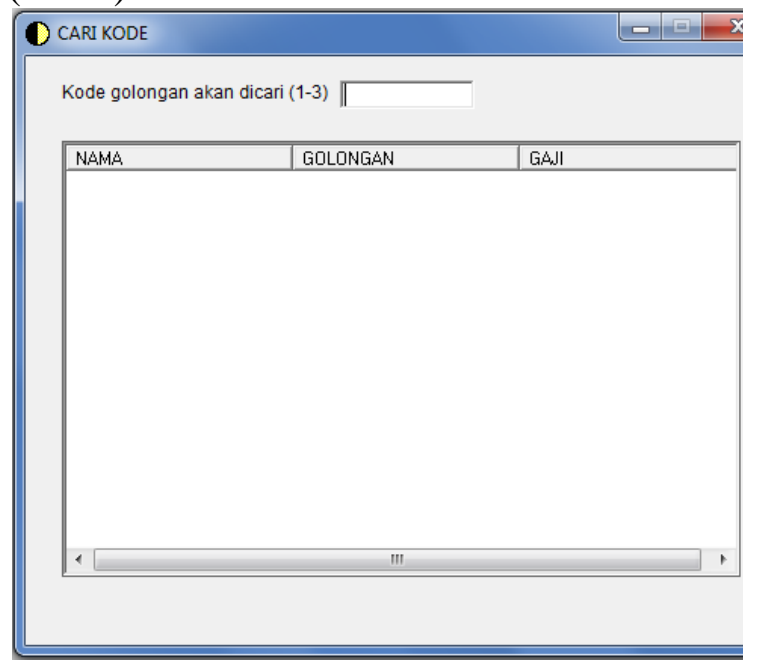

Gambar 4. Halaman pencarian data guru berdasarkan kode golongan

Pada halaman tersebut terdapat tombol cari yang digunakan untuk mencari data guru berdasarkan kode golongan masing-masing guru. Setelah data guru diketahui pengambil keputusan diminta mengisi bobot masing-masing kriteria dan dengan menekan tombol hitung bobot maka dapat diketahui nilai masing-masing bobot kriteria.

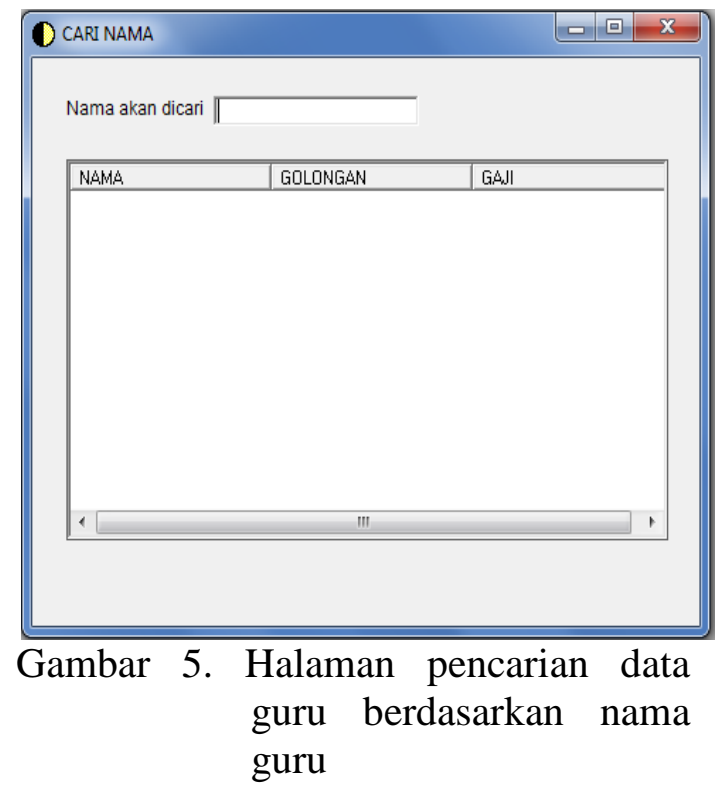

\section{Kesimpulan}

Metode Simple Additive Weighting (SAW) diterapkan dalam sistem pendukung keputusan sehingga dapat menentukan pemilihan guru terbaik. Sistem yang dibangun dapat mempermudah sekolah dalam menentukan pemilihan guru terbaik. Dengan menerapkan sistem komputerisasi dalam pemilihan guru terbaik, maka proses pengolahan data akan semakin tepat dan mengurangi kesalahan dalam perhitungan nilai serta mendapatkan hasil perangkingan yang baik. Dengan menggunakan database, data guru atau hasil penilaian dapat tersimpan di dalamnya, sehingga jika terjadi kesalahan dalam penginputan data guru serta data penilaian, maka data yang salah tersebut dapat diperbaiki tanpa harus menginput ulang datanya. 


\section{Daftar Pustaka}

[1] Prasetyowati, Khoirunnisa Rahma, dan Sutojo,.T. Sistem Pendukung Keputusan Penilaian Kinerja Guru (Pkg) Menggunakan Metode Simple Additive Weighting(SAW) SMA Negeri 9 Semarang.

Skripsi. Semarang: UDINUS. 2013.

[2]Penyusun, T. (2011). Pedoman Pelaksanaan Penilaian Kinerja Guru (PK Guru). Kemendiknas.

[3] Paudni.Kemdikbud.'Kompetensi Guru.pdf". Home page on-line. Available from http://www.paudni.kemdikbud.go.id/ wpcontent/uploads/2012/08/Permen1 62007KompetensiGuru.pdf; Internet; accessed August 2008.

[4]Buku-2-pedoman-pkg. Home page On-line. Available from http://www.ekinerjaguru.org; Internet; accessed July 2012

[5] Dewantoro, Aji. Sistem Pendukung Keputusan Menentukan Guru Teladan Di SMPN 24 Semarang Dengan Menggunakan Metode Simple Additive Weighting. Tugas Akhir. Semarang : UDINUS.2013 